\title{
Protein acetylation in mitochondria plays critical functions in the pathogenesis of fatty liver disease
}

Zhang Le-tian ${ }^{\dagger}$, Hu Cheng-zhang ${ }^{\dagger}$, Zhang Xuan, Qin Zhang, Yan Zhen-gui, Wei Qing-qing, Wang Sheng-xuan, Xu Zhong-jin, Li Ran-ran, Liu Ting-jun, Su Zhong-qu, Wang Zhong-hua and Shi Ke-rong* (D)

\begin{abstract}
Background: Fatty liver is a high incidence of perinatal disease in dairy cows caused by negative energy balance, which seriously threatens the postpartum health and milk production. It has been reported that lysine acetylation plays an important role in substance and energy metabolism. Predictably, most metabolic processes in the liver, as a vital metabolic organ, are subjected to acetylation. Comparative acetylome study were used to quantify the hepatic tissues from the severe fatty liver group and normal group. Combined with bioinformatics analysis, this study provides new insights for the role of acetylation modification in fatty liver disease of dairy cows.

Results: We identified 1841 differential acetylation sites on 665 proteins. Among of them, 1072 sites on 393 proteins were quantified. Functional enrichment analysis shows that higher acetylated proteins are significantly enriched in energy metabolic pathways, while lower acetylated proteins are significantly enriched in pathways related to immune response, such as drug metabolism and cancer. Among significantly acetylated proteins, many mitochondrial proteins were identified to be interacting with multiple proteins and involving in lipid metabolism. Furthermore, this study identified potential important proteins, such as HADHA, ACAT1, and EHHADH, which may be important regulatory factors through modification of acetylation in the development of fatty liver disease in dairy cows and possible therapeutic targets for NAFLD in human beings.

Conclusion: This study provided a comprehensive acetylome profile of fatty liver of dairy cows, and revealed important biological pathways associated with protein acetylation occurred in mitochondria, which were involved in the regulation of the pathogenesis of fatty liver disease. Furthermore, potential important proteins, such as HADHA, ACAT1, EHHADH, were predicted to be essential regulators during the pathogenesis of fatty liver disease. The work would contribute to the understanding the pathogenesis of NAFLD, and inspire in the development of new therapeutic strategies for NAFLD.
\end{abstract}

Keywords: Acetylome, Lipid metabolism, Fatty liver, Dairy cattle, Perinatal period

\footnotetext{
* Correspondence: krshi@sdau.edu.cn

${ }^{\dagger}$ Zhang Le-tian and Hu Cheng-zhang contributed equally to this work.

Shandong Key Laboratory of Animal Bioengineering and Disease Prevention, College of Animal Science and Technology, Shandong Agricultural University, No. 61 Daizong Street, Taian, Shandong 271018, P. R. China
}

(c) The Author(s). 2020 Open Access This article is licensed under a Creative Commons Attribution 4.0 International License, which permits use, sharing, adaptation, distribution and reproduction in any medium or format, as long as you give appropriate credit to the original author(s) and the source, provide a link to the Creative Commons licence, and indicate if changes were made. The images or other third party material in this article are included in the article's Creative Commons licence, unless indicated otherwise in a credit line to the material. If material is not included in the article's Creative Commons licence and your intended use is not permitted by statutory regulation or exceeds the permitted use, you will need to obtain permission directly from the copyright holder. To view a copy of this licence, visit http://creativecommons.org/licenses/by/4.0/. The Creative Commons Public Domain Dedication waiver (http://creativecommons.org/publicdomain/zero/1.0/) applies to the data made available in this article, unless otherwise stated in a credit line to the data. 


\section{Background}

More than $60 \%$ of dairy cows develop fatty liver during the transition period from dry milk to lactation due to negative energy imbalance [1], resulting in weakened liver function and decreased milk production [2]. The fatty liver disease in dairy cows is a typical type of nonalcoholic fatty liver disease (NAFLD), mainly caused by obesity and stress response. In the first month after delivery, $5-10 \%$ of dairy cows had a severe form of fatty liver, and $30-40 \%$ had mild or moderate fatty liver [3]. The occurrence of fatty liver in dairy cows leads to huge economic losses, not only because of decreased milk production but also because of prolonged calving intervals and weakened reproductive performance $[4,5]$, and therefore shortened their service life.

As an important type of protein post-translational modification, lysine $(\mathrm{K})$ acetylation modification can change the protein-protein interactions, protein homeostasis, catalytic activity, and subcellular localization of metabolic enzymes [6,7], as well as affect the structure of cell chromatin or activate transcriptional regulators in the nucleus [8]. Acetylation plays particular important roles in material and energy metabolism by modifying the activity and/or specificity of certain enzymes and substrates, thereby regulating glucose [9-11], lipid, and amino acid metabolism. Human-related studies have indicated that the change in protein acetylation pattern is associated with the occurrence and/or development of metabolic-related diseases such as obesity, cardiovascular disease, diabetes, and tumorigenesis [12, 13]. In particular, in livers, it has been predicted that acetylation modification is involved in most metabolic pathways by regulating glycolipid metabolism and urea cycles [14]. Fatty liver disease in dairy cows is a type of metabolic disorder. Little is known about the pathogenesis of perinatal fatty liver in dairy cows [15]. The objective of the present study is to investigate the possible role of protein acetylation in liver function during the transition period from dry milk to lactation in dairy cattle.

TMT labeling technology is a peptide in vitro labeling technology developed by Thermo Scientific, USA. The technology uses ten isotopic labels to label the amino groups of the peptide. After LC-MS/MS analysis, the relative content of protein in ten different samples can be compared simultaneously. TMT technology is a commonly used differential proteomics technology, which is widely used in the field of disease marker screening, drug targets, animal disease resistance/anti-stress mechanisms, animal and plant development, and differentiation mechanisms. The TMT labeling technology has the advantages of high sensitivity, wide application range, fast analysis speed, and good separation effects.

In this study, we focused on the protein acetylation modification in liver tissue of cows with severe fat deposition, and healthy livers. In this project, differentially acetylated proteins were identified through bioinformatics analyses which were carried out by combing a series of advanced technologies, such as TMT-labeled acetylated peptide enrichment and mass spectrometrybased quantitative proteomics. This study reveals a comprehensive acetylome profiling of fatty liver disease in dairy cattle and identifies potential biomarkers based on protein acetylation level. These results provide a strong foundation for further understanding of important protein regulatory targets in the development of NALFD in human beings and/or animals.

\section{Results}

\section{Overview of acetylation}

The tissues of normal (Norm1, Norm2, Norm3) and fatdeposited (FL1, FL2, FL3) livers were obtained for acetylome profiling. Oil red $\mathrm{O}$ staining results of the liver tissue samples showed that there was a significant difference between the fatty liver group $(86.75 \% \pm 4.83 \%$, $n=6)$ and the normal liver group $(6.26 \% \pm 5.23 \%, n=8)$ (Fig. 1a, b). The experimental workflow of this study is shown in Fig. 1c. The thermal maps of Pearson correlation coefficients, calculated upon log 2 logarithm conversion of the relative peptide quantitative values so as to obey the normal distribution, between two group samples were averaged at 0.74 in the Norm group and 0.80 in the FL group, indicating that the biological replicates within the group met the standard of quantitative consistency (Fig. S1A). Additionally, the distribution of peptide mass errors is close to zero, and most of them are less than $5 \mathrm{ppm}$ (Fig. S1B). Moreover, the length of the peptide segments showed a theoretical distribution (Fig. S1C). These results indicated appropriate sample preparation and credible data quality.

In total, 1841 differential acetylation sites on 665 proteins were identified. Among them, 1072 sites on 393 proteins were quantified, 307 sites on 122 proteins were significantly higher acetylated (fold-change $>1.2, P<0.05$ ), and 358 sites on 213 proteins were significantly lower acetylated (fold-change $<1 / 1.2, P<0.05$ ). Among them, 19 proteins are both higher acetylated and/or lower acetylated at different positions (Table 1, Table S1). The number of acetylation sites on the acetylated proteins was different (Fig. 2a). The number of proteins with only one acetylation site was more than half $(59.2 \%, 187 / 316)$. The proportion of proteins with two, three, and more than four acetylation sites was $16.1 \%(51 / 316), 11.1 \%$ (35/316), and $13.6 \%$ (43/316), respectively. There were 21 proteins containing $>6 \mathrm{Kac}$ sites of which HADHA, ANXA6, CPS1, GOT2, HMGCS2, and ACAT1 are highly acetylated (Table 2). Significance analysis showed that differentially acetylated proteins (DAPs) enriched in fatty acid oxidation pathway were significantly higher acetylated, 


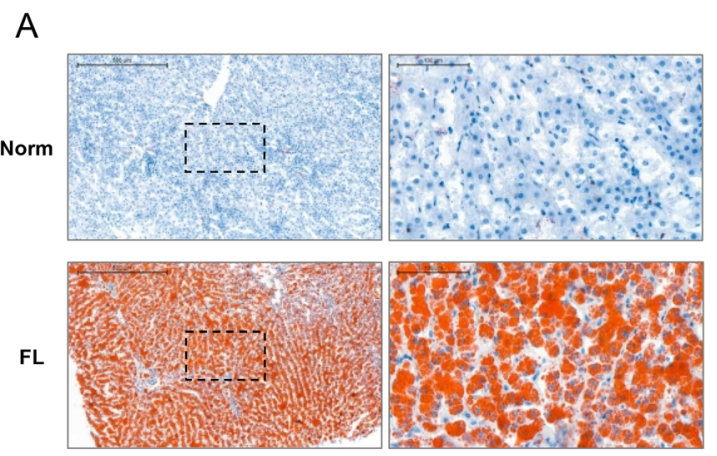

B
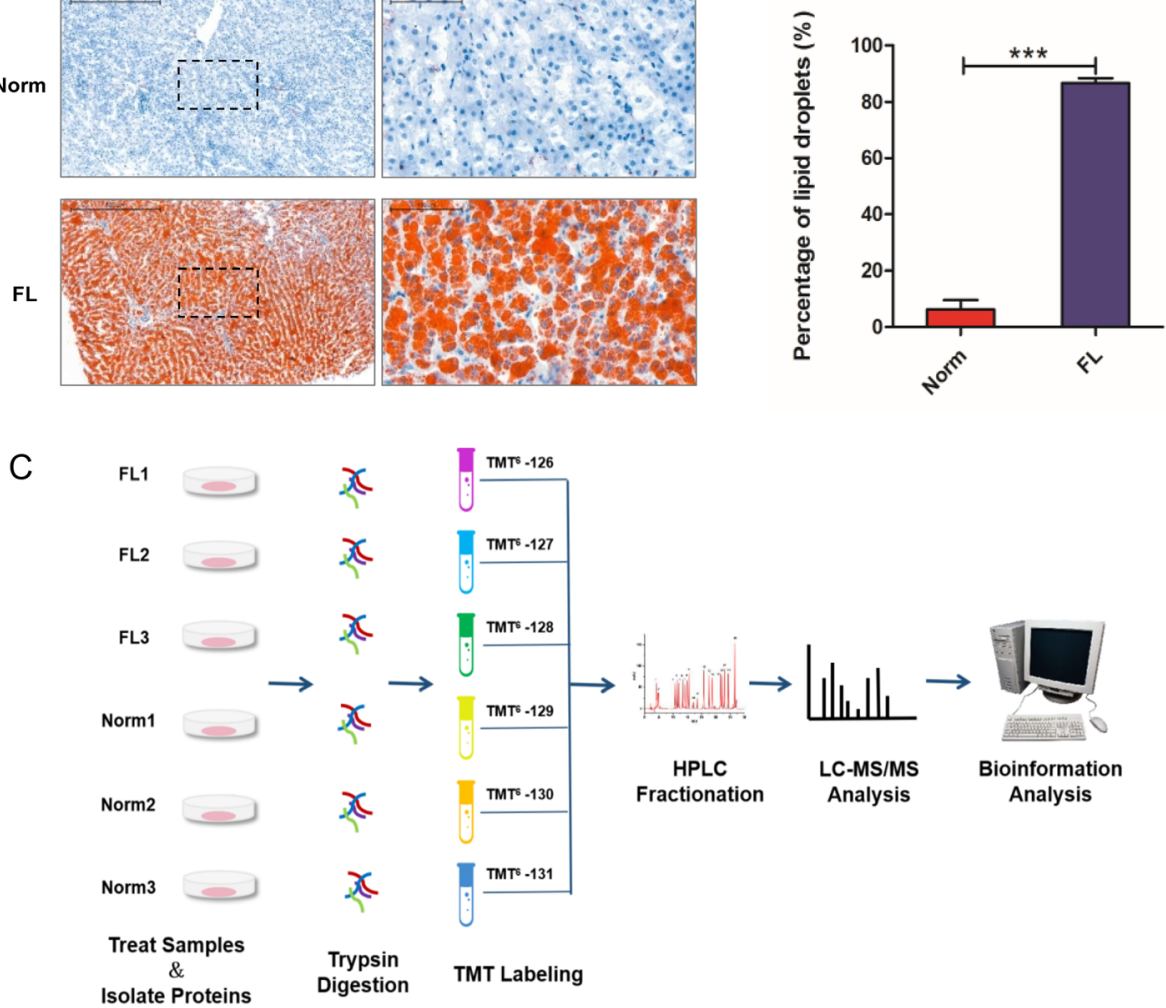

Fig. 1 Liver sample selection and study design. a Representative hepatic histology sections of liver tissues from dairy cows during partuition period. Oil Red O staining assay was used for fat content assessment in hepatic cells, therefore classified into normal liver (Norm) and fatty liver (FL), scale bar $500 \mu \mathrm{m}$. Blue dots indicate cell nucleus. Brown or red indicate lipid drops in cells that disovled Oil red. The right panel is a highpowered magnification of the black dashed area in the left panel. $\mathbf{b}$ Comparison of average percentage of hepatocytes containing lipid droplets in liver from Norm $(n=6)$ and FL $(n=8)$ groups. ${ }^{* *} P<0.001$. $\mathbf{c}$ The whole experimental work-flow for the study

such as HADHA, HADHB, ACAA2, ACADM, and ACADVL. DAPs promoting ketosome synthesis and enzymes involved in energy metabolism were also significantly higher acetylated, such as HMGCS2, ACAT1, PCK2, IDH2, MDH2, and SUCLG1. Proteins that are molecule transport-related were significantly lower acetylated, such as FABP1, ANXA6, and SCP2 (Fig. 2b). These results suggest that the metabolites transport in the liver tissue with fat deposition significantly inhibited. Although energy metabolism and fatty acid oxidation were enhanced, the accumulation of fat in the liver was unavoidable. In addition, among all the identified DAPs, it was found that $36.7 \%(116 / 316)$ were localized to mitochondria, with $74.1 \%(86 / 116)$ of these proteins higher acetylated (Fig. 2c). Moreover, as for all the Kac sites, $46.6 \%$
(310/335) of them were again localized in the mitochondria, with $84.5 \%(262 / 310)$ of these sites higher acetylated (Fig. 2d). This suggests that proteins that were associated with mitochondrial function were critical for the liver metabolism, and protein acetylation played an essential role during the development of fatty liver disease in dairy cattle.

\section{Analysis of Kac motifs}

To explore the preference for lysine acetylation sites, motif- $x$ was used to detect the amino acid occupancy frequency at the location around the identified modification sites. These motifs exhibit different abundances (Fig. 3a), with the KacK $(19.2 \%, 245 / 1275)$, KacS (13.7\%, $175 / 1275)$, KacT $(10.6 \%, 135 / 1275)$, and $\mathrm{KacH}(10.4 \%$, 132/1275) motifs being the most common (Fig. 3b, c).

Table 1 Statistical results of differentially lysine acetylated (Kac) sites and proteins

\begin{tabular}{lllll}
\hline Items & Identified & Quantified & Higher acetylated $(>1.2)$ & Lower acetylated $(<1 / 1.2)$ \\
\hline Kac sites & 1841 & 1072 & 307 & 358 \\
Proteins & 605 & 393 & 122 & 213 \\
\hline
\end{tabular}


A

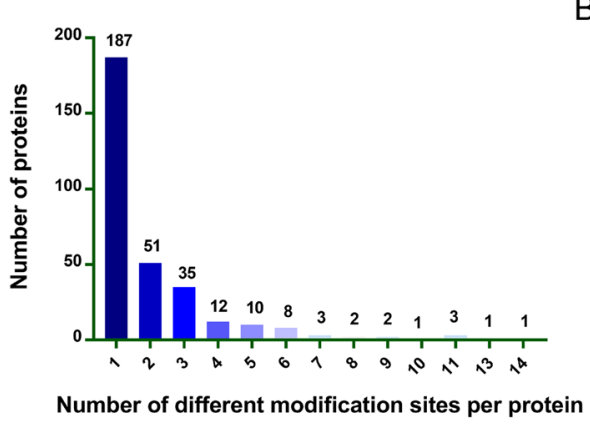

C

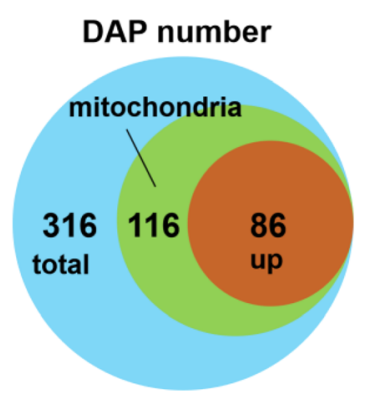

B
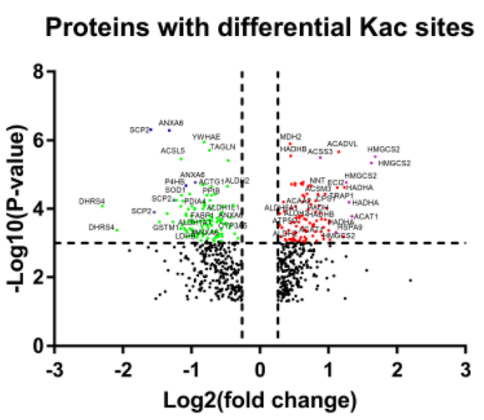

D

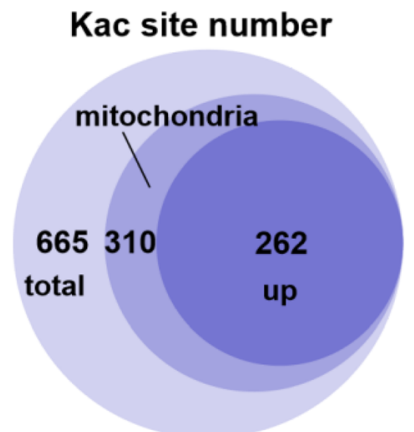

Fig. 2 The identified differentially lysine acetylated (Kac) proteins and/or sites mainly localized to mitochondria. a Number distribution of different Kac sites on proteins. $\mathbf{b}$ Volcano plot of statistical significance against log2-fold change between the Norm group $(N=3)$ and $F L$ group $(N=3)$, showing significantly differentially expressed proteins colored in green and red. c Among the identified differentially acetylated proteins (DAPs), the DAPs with higher acetylation levels mainly located in mitochondria, account for a large proportion (86/116) of all identified DAPs. $\mathbf{d}$ Among the identified differentially Kac sites, the up-regulated Kac sites located in the mitochondria, account for a large proportion (310/335) of all identified Kac sites

The results of the motif analysis showed that the residues of histidine $(\mathrm{H})$, lysine $(\mathrm{K})$, and serine $(\mathrm{S})$ were highly enriched at the +1 position near the Kac site, and the aspartic acid (D) was observed at the -1 position. Glutamate (E) enrichment was observed at the +2 position (Fig. 3c).

Structural analysis of proteins containing lysine was performed using NETSURFP software, so as to understand the locations of acetylated and/or non-acetylated lysine in the secondary structures of proteins (alpha-helix, betastrand and coil). Results indicated that significantly less acetylated sites were in the beta-strand $(P=0.009)$ or surface-accessible $(P=0.022)$ than non-acetylated sites (Fig. 3d). However, for lysine located in the alpha-helix and/or coil region, there was no statistical difference between acetylated and/or non-acetylated lysine.

\section{Functional enrichment analysis of differentially acetylated proteins}

To further understand the functions and features of the identified differentially modified proteins, functional enrichment and cluster analysis were performed. Gene Ontology (GO) analysis was carried out and assessed the biological processes, molecular functions, and cellular components of these identified proteins to attend. The Kac proteins were all cellular component located in cell, organelle, membrane and/or extracellular region (Fig. S2A). Mitochondria and cytoplasm are the main distributed areas in the cell for the Kac proteins (Fig. S2B). The identified Kac proteins mainly belonged to the metabolic, cellular, and single biological processes and biological regulation (Fig. S2C). Binding and catalytic activity are the major functions of the identified Kac proteins (Fig. S2D). Actually, the KEGG pathway enrichment analysis showed that Kac protein was mainly involved in propanoate metabolism, valine, leucine, and isoleucine degradation, and glyoxylate and dicarboxylate metabolism (Fig. 4a). Loweracetylated proteins are significantly enriched in pathways such as substance metabolism, protein processing and/or glycolysis/gluconeogenesis in hepatocytes (Fig. 4b), while higher-acetylated proteins are significantly enriched in energy/amino acid metabolism-related and/or biosynthesis pathways (Fig. 4c). These results suggest that acetylation modification mainly modulates the cellular biological processes that are closely associated with mitochondria function, which is critical to the energy metabolism in liver. In another word, the pathogenesis of fatty liver disease in dairy cows were presumed to be closely related to the 
Table 2 The background information and their distribution of differentially acetylated sites at lysines in proteins

\begin{tabular}{|c|c|c|c|c|c|c|c|}
\hline $\begin{array}{l}\text { Protein accession } \\
\text { number }\end{array}$ & $\begin{array}{l}\text { Protein } \\
\text { name }\end{array}$ & $\begin{array}{l}\text { Number of } \\
\text { potential } \\
\text { modification } \\
\text { sites }\end{array}$ & $\begin{array}{l}\text { Number of } \\
\text { differentially } \\
\text { acetylated sites }\end{array}$ & Position & Modified sequence ${ }^{\mathbf{a}}$ & $\begin{array}{l}\text { Average fold } \\
\text { change of } \\
\text { acetylated level } \\
\text { by FL/Norm }\end{array}$ & $\begin{array}{l}\text { Maximum } \boldsymbol{P} \\
\text { value }^{b}\end{array}$ \\
\hline Q3SZ00 & HADHA & 23 & 14 & 516 & MQLLEIITTEK(1)TSK & $\begin{array}{l}1.50 \pm 0.49(n= \\
14)\end{array}$ & $\leq 0.0469$ \\
\hline P79134 & ANXA6 & 17 & 13 & 306 & SLYSMIK(1)NDTSGEYK & $\begin{array}{l}0.59 \pm 0.11(n= \\
13)\end{array}$ & $\leq 0.0473$ \\
\hline F1ML89 & CPS1 & 35 & 11 & 875 & LTSIDK(1)WFLYK & $\begin{array}{l}1.31 \pm 0.25(n= \\
11)\end{array}$ & $\leq 0.0179$ \\
\hline P12344 & GOT2 & 16 & 11 & 90 & K(1)AEAQIAAK(1)NLDK & $\begin{array}{l}1.31 \pm 0.25(n= \\
11)\end{array}$ & $\leq 0.0354$ \\
\hline Q2KIE6 & HMGCS2 & 13 & 11 & 350 & LEDTYTNK(1)DVDK(1)AFLK & $\begin{array}{l}1.96 \pm 0.82(n= \\
11)\end{array}$ & $\leq 0.0496$ \\
\hline Q29RZ0 & ACAT1 & 14 & 10 & 197 & IHMGNCAENTAK(1)K & $\begin{array}{l}1.86 \pm 0.38(n= \\
10)\end{array}$ & $\leq 0.0169$ \\
\hline AOA140T871 & GLUD1 & 18 & 9 & 460 & LTFK(1)YER & $\begin{array}{l}1.42 \pm 0.30(n= \\
9)\end{array}$ & $\leq 0.0495$ \\
\hline F1N7K8 & ALDH6A1 & 10 & 9 & 333 & K(1)WLPELVER & $\begin{array}{l}1.34 \pm 0.30(n= \\
9)\end{array}$ & $\leq 0.0246$ \\
\hline F1MQV8 & ACSS3 & 13 & 8 & 124 & HIENGK(1)GDK & $\begin{array}{l}1.68 \pm 0.24(n= \\
8)\end{array}$ & $\leq 0.0083$ \\
\hline Q3ZCHO & HSPA9 & 10 & 8 & 612 & LK(1)EEISK & $\begin{array}{l}1.41 \pm 0.43(n= \\
8)\end{array}$ & $\leq 0.0302$ \\
\hline Q3T0R7 & ACAA2 & 11 & 7 & 240 & QTMQVDEHPRPQTTMEQLNK(1)LPPVFK(1)K & $\begin{array}{l}1.47 \pm 0.41(n= \\
7)\end{array}$ & $\leq 0.0416$ \\
\hline F1MV74 & SCP2 & 9 & 7 & 189 & NHK(1)HSVNNPYSQFQK & $\begin{array}{l}0.37 \pm 0.07(n= \\
7)\end{array}$ & $\leq 0.0017$ \\
\hline Q5E9F8 & $\mathrm{H} 3 \mathrm{~F} 3 \mathrm{~A}$ & 8 & 7 & 28 & K(1)SAPSTGGVK(0.857)K(0.143)PHR & $\begin{array}{l}0.58 \pm 0.06(n= \\
7)\end{array}$ & $\leq 0.0426$ \\
\hline Q32LG3 & $\mathrm{MDH} 2$ & 14 & 6 & 328 & ASIK(1)K(1)GEEFVK & $\begin{array}{l}1.53 \pm 0.21(n= \\
6)\end{array}$ & $\leq 0.0017$ \\
\hline F1N206 & DLD & 12 & 6 & 159 & ITGK(1)NQVTATK & $\begin{array}{l}1.26 \pm 0.36(n= \\
6)\end{array}$ & $\leq 0.0191$ \\
\hline P05307 & $\mathrm{P} 4 \mathrm{HB}$ & 11 & 6 & 387 & NFEEVAFDEK(1)K & $\begin{array}{l}0.56 \pm 0.06(n= \\
6)\end{array}$ & $\leq 0.0151$ \\
\hline P20000 & $\mathrm{ALDH} 2$ & 11 & 6 & 371 & TEQGPQVDETQFK(1)K & $\begin{array}{l}1.26 \pm 0.29(n= \\
6))\end{array}$ & $\leq 0.0176$ \\
\hline O46629 & $\mathrm{HADHB}$ & 10 & 6 & 189 & MMLDLNK(1)AK(1)TLAQR & $\begin{array}{l}1.43 \pm 0.34(n= \\
6)\end{array}$ & $\leq 0.0350$ \\
\hline QOVCM4 & PYGL & 9 & 6 & 465 & IHSDIVK(1)TQVFK & $\begin{array}{l}0.61 \pm 0.08(n= \\
6)\end{array}$ & $\leq 0.0433$ \\
\hline F1MZP8 & - & 7 & 6 & 348 & LVTDFMAK(1)K & $\begin{array}{l}0.70 \pm 0.06(n= \\
6)\end{array}$ & $\leq 0.0358$ \\
\hline P52898 & - & 7 & 6 & 161 & DAGLTK(1)SIGVSNFNHK & $\begin{array}{l}0.63 \pm 0.09(n= \\
6)\end{array}$ & $\leq 0.0217$ \\
\hline
\end{tabular}

a Shown is the distribution range of $P$-values of all the aceltylated sites in this protein by picking up the ultimate value

${ }^{b}$ Identified peptide sequence containing acetylated modification sites marked with localization and probabilities

dysfunction of mitochondrial metabolism, and lysine acetylation of target proteins could be one of the pivotal modification manners during the process.

According to the modification levels of the acetylated proteins, they were classified into four parts according to their fold changes (Fig. 5a): Q1 (226 DAPs, $0<$ Ratio $\leq 1 /$ 1.5), Q2 (132 DAPs, 1/1.5 < Ratio $\leq 1 / 1.2$ ), Q3 (193 DAPs,
$1.2<$ Ratio $\leq 1.5)$ and Q4 (114 DAPs, Ratio > 1.5). Then, enrichment analysis of GO, KEGG, and protein domains for proteins in each Q group were performed, Results indicated that the higher and lower Kac proteins enriched in distinct biological processes, cell components, molecular functions, protein domains, and/or KEGG pathways. Acetylated proteins in Q1 class (Fig. 5b), which are extremely 


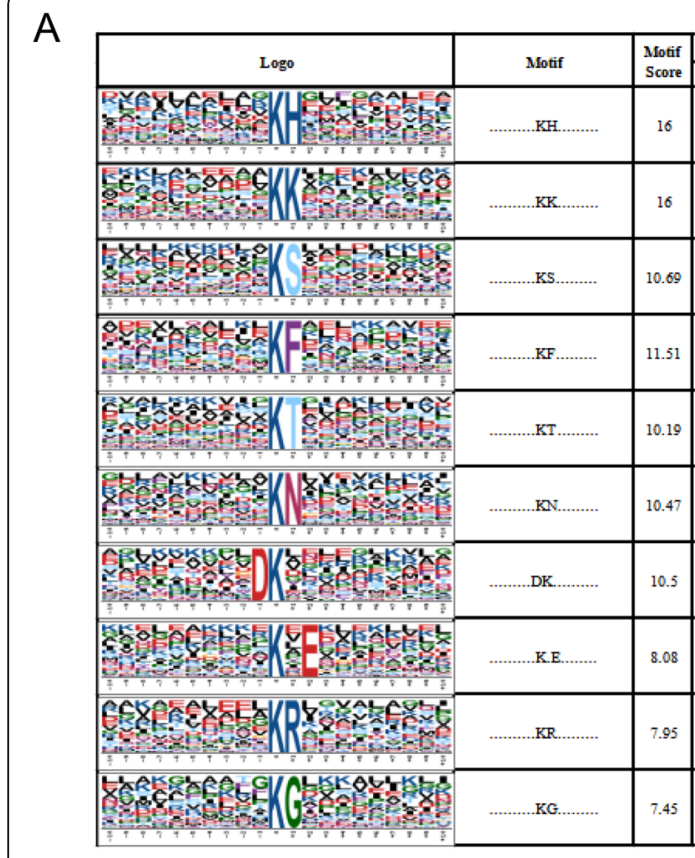

C

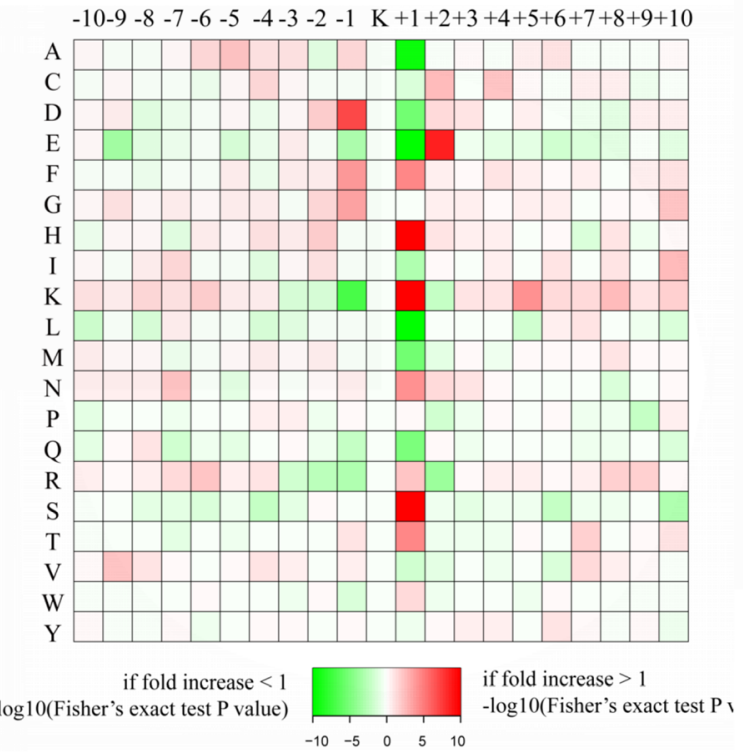

B

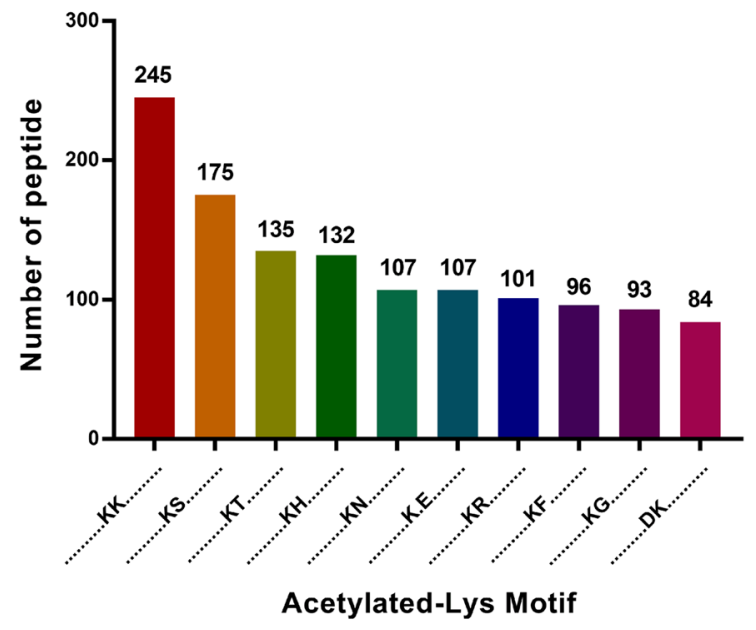

$\mathrm{D}$

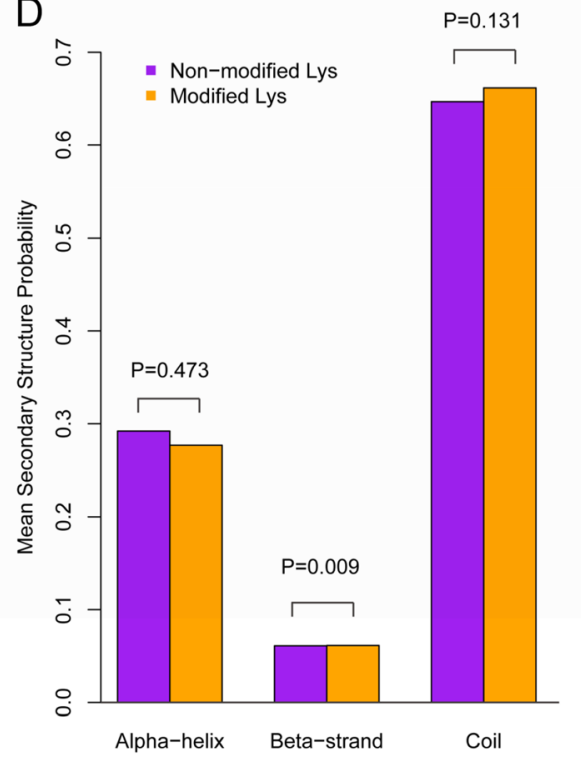

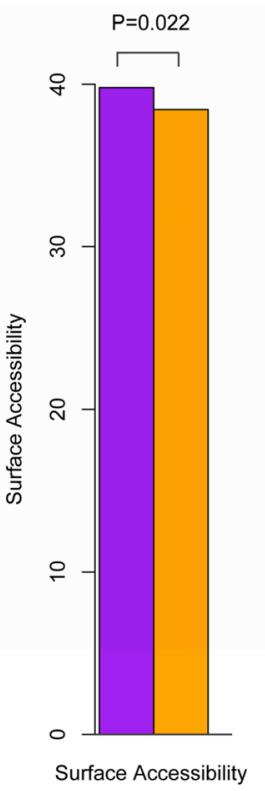

Fig. 3 Motif analysis of the identified acetylation peptides. a Probable sequence motifs of acetylation sites in fatty liver tissues identified using Motif-X. $\mathbf{b}$ Number of identified peptide containing acetylated lysines and their probable motifs. $\mathbf{c}$ Heat map showing the relative frequencies of amino acids in specific positions, including enrichment (red) or depletion (green) of amino acids flanking the acetylated lysine in fatty liver proteins. $\mathbf{d}$ Location probabilities of acetylated and/or non-acetylated lysines in protein secondary structures (alpha-helix, beta-strand, and coil) and surface accessibility

downregulated, are widely involved in multiple biological processes and pathways, mainly including drug metabolism - cytochrome P450, metabolism of xenobiotics by cytochrome P450, apoptosis, chemical carcinogenesis, hepatocellular carcinoma, and steroid biosynthesis. Loweracetylated proteins in Q2 class mainly localize in membranes (Fig. 5c) and participate in the regulation of macromolecule metabolism and protein, transmembrane, and ion transport that are related to ion upchannels and gated channels. These acetylated proteins are significantly involved in the PPAR signaling pathway and the amino acid metabolism pathway, such as the tyrosine and tryptophan metabolism pathway. Therefore, it suggests that the downregulation of protein acetylation was mainly involved 


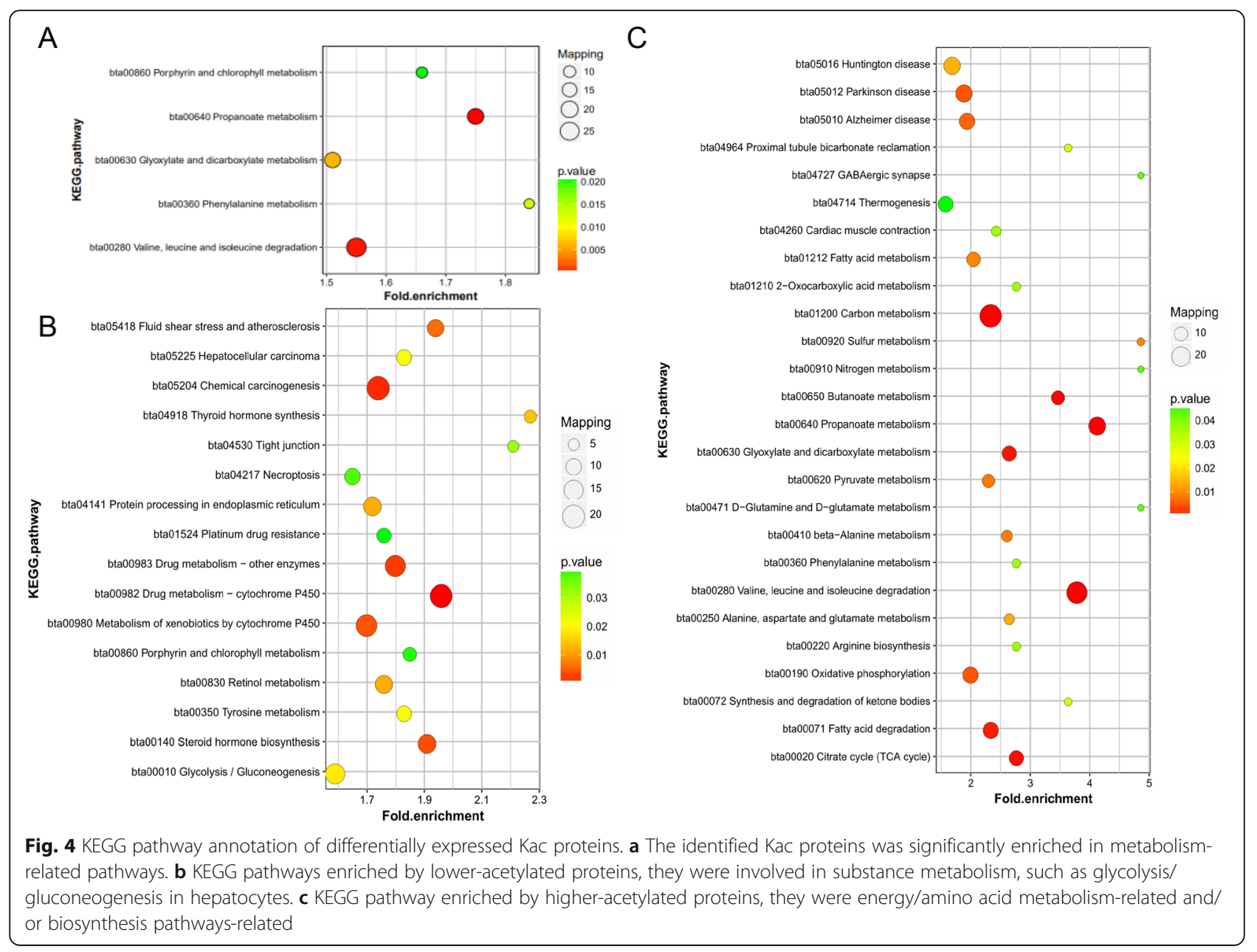

in protein transport, cell communication and steroid biosynthesis, causing dysfunction in cell apoptosis and cell transport, thereby pathological metabolism in hepatocytes.

The proteins with higher acetylation levels in Q3 and Q4 class got overlapping enrichment preference (Fig. 5d). Both Q3 and Q4 proteins are mitochondriaassociated and participate in multiple acyl-CoA metabolic processes by altering the activities of acyl-CoA synthetase, acyl-CoA dehydrogenase and acyl-CoA transferase. The KEGG pathway analysis showed that these acetylated proteins were enriched in fatty acid metabolism, pyruvate metabolism, ketone synthesis and degradation, and multiple amino acid metabolism pathways, such as D-glutamine and D-glutamate metabolism, lysine degradation, phenylalanine metabolism, alanine, aspartate and glutamate metabolism, and arginine biosynthesis (Fig. $5 \mathrm{~d}$ ). These data suggest that the upregulation of protein acetylation might significantly affect energy metabolism pathways, especially tricarboxylic acid cycle that are involved the hepatic mitochondrial function, and thereby causing amino acid and lipid metabolic disorders.
Additionally, these acetylated proteins are predicted to form protein-protein interaction network, with 209 nodes and 975 interactions (Fig. 6) Notably, 15 proteins were found to be simultaneously higher acetylated and/ or lower acetylated on a single target protein at different positions. Among interaction network, four highly interconnected protein clusters were highlighted via the MCODE algorithm, they are involved in valine, leucine, and isoleucine degradation, oxidative phosphorylation, chemical carcinogenesis and ribosomes (Fig. S3).

\section{Identification of potential important hepatic proteins as acetylation targets}

Some of the identified differentially acetylated proteins are abundantly and frequently interacting with other proteins (Fig. 6), indicating their potential important function in maintaining normal liver metabolism. However, part of the acetylated proteins contain multiple modification sites. As for the acetylated sites in a single protein, some are significantly higher acetylated and some are significantly lower acetylated (Table 3), such as enoyl-CoA hydratase and 3-hydroxyacyl CoA 


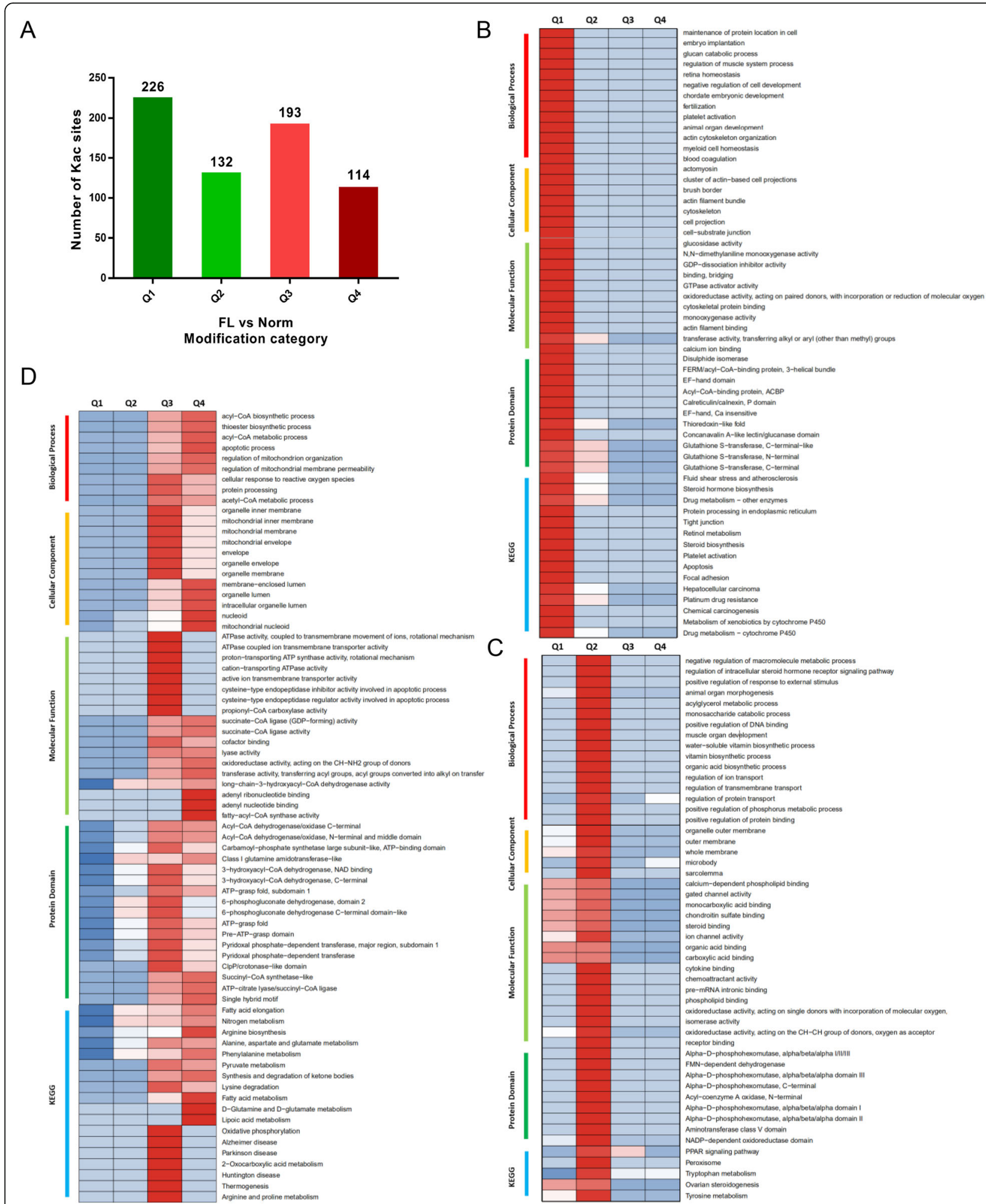

Fig. 5 (See legend on next page.) 
(See figure on previous page.)

Fig. 5 Cluster analysis of differential Kac proteins based on their biological processes, cellular components, molecular functions, protein domains and/or enriched KEGG pathways. a Distribution of differential acetylation sites as per their fold changes. The differentially expressed proteins were classified into four groups according to their differentially expressed folds: Q1 $(0<$ Ratio $\leq 1 / 1.5)$, Q2 (1/1.5 < Ratio $\leq 1 / 1.2)$, Q3 (1.2< Ratio $\leq 1.5)$ and Q4 (Ratio > 1.5). b Cluster analysis of the DAPs classified into the Q1 class. c Cluster analysis of DAPs classified into Q2 class. $\mathbf{d}$ Cluster analysis of DAPs classified into Q3 and Q4 class

dehydrogenase (EHHADH), hydroxyacyl-CoA dehydrogenase trifunctional multienzyme complex subunit alpha (HADHA), acetyl-CoA acetyltransferase 1 (ACAT1), etc. These proteins are all mitochondria-localized proteins, and they can interact with many other proteins and participate in multiple lipid metabolism-related pathways and/or tricarboxylic acid cycle (Table 3).

EHHADH is a dehydrogenase involved in the fatty acid $\beta$ oxidation and is one of the four essential enzymes in the peroxisome $\beta$ oxidation pathway. Ehhadh was

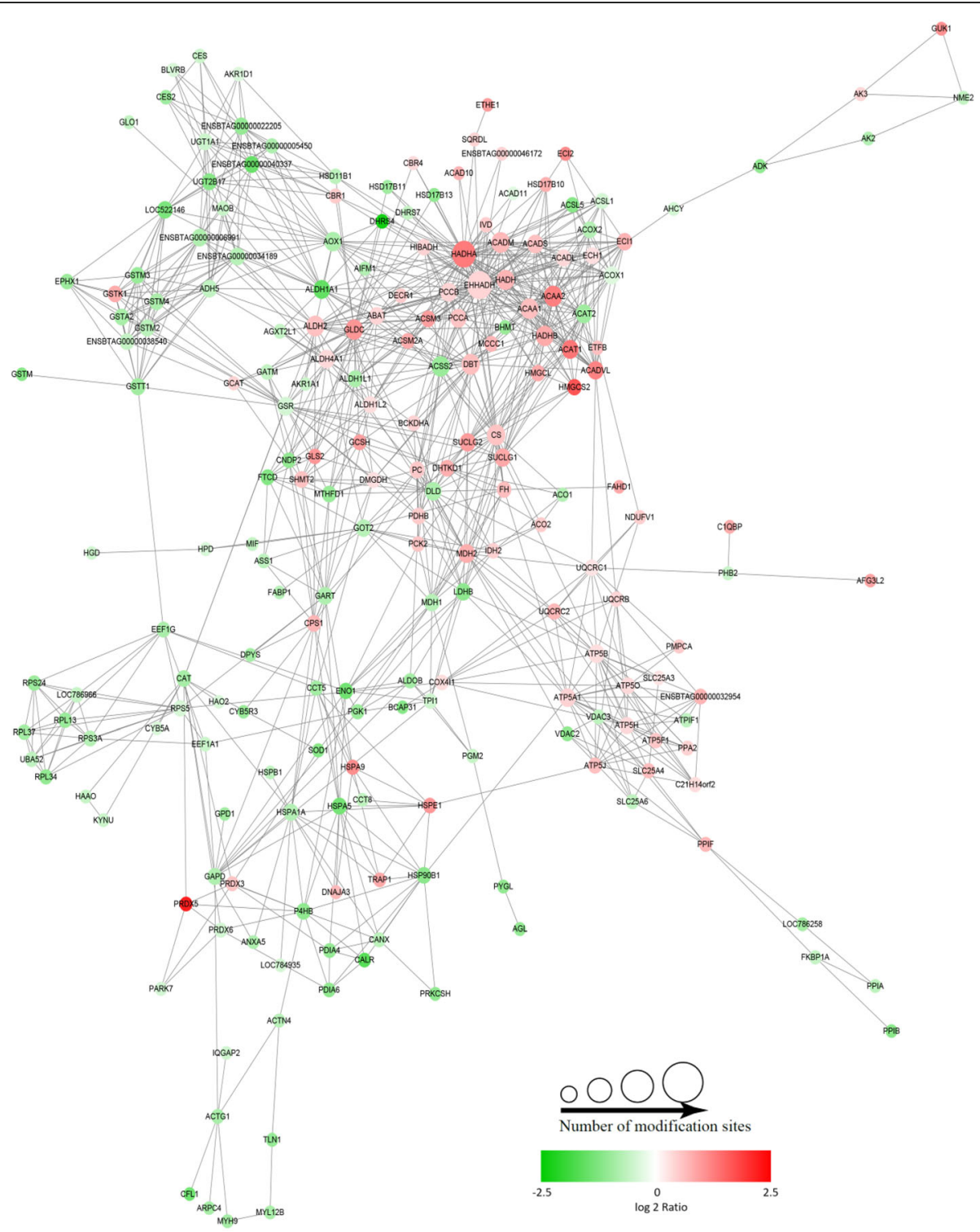

Fig. 6 Identification of highly enriched protein-protein interaction clusters. In the interaction network, each acetylated protein was represented by a circle. The size of the circle indicates the number of acetylation sites in the protein. The color of the circle indicates the modified directions of the acetylated sites in the protein, red presents higher-acetylated sites and greed presents lower-acetylated sites 
Table 3 Potentially essential proteins as acetylation targets for maintaining normal hepatic metabolism

\begin{tabular}{|c|c|c|c|c|c|c|}
\hline $\begin{array}{l}\text { Protein accession } \\
\text { number }\end{array}$ & $\begin{array}{l}\text { Protein } \\
\text { name }\end{array}$ & $\begin{array}{l}\text { All/Up/ } \\
\text { Down }\end{array}$ & $\begin{array}{l}\text { Protein subcellular } \\
\text { localization }\end{array}$ & $\begin{array}{l}\text { No. of interactive } \\
\text { nodes in }\left.\mathrm{PPI}\right|^{\mathbf{b}}\end{array}$ & $\begin{array}{l}\text { No. of associated } \\
\text { pathways }\end{array}$ & Signaling pathways \\
\hline $\mathrm{E} 1 \mathrm{BMH} 4$ & EHHADH & $2 / 1 / 1$ & mitochondria & 53 & 11 & $\begin{array}{l}\text { Fatty acid degradation; Valine, leucine and } \\
\text { isoleucine degradation; Tryptophan metabolism; } \\
\text { Peroxisome; beta-Alanine metabolism; Butanoate } \\
\text { metabolism; PPAR signaling pathway; Propanoate } \\
\text { metabolism; Fatty acid metabolism; Lysine } \\
\text { degradation; Carbon metabolism; }\end{array}$ \\
\hline Q3SZ00 & HADHA & $\begin{array}{l}14 / 12 / \\
2\end{array}$ & mitochondria & 48 & 11 & $\begin{array}{l}\text { Fatty acid degradation; Valine, leucine and isoleucine } \\
\text { degradation; Tryptophan metabolism; beta-Alanine } \\
\text { metabolism; Butanoate metabolism; Propanoate } \\
\text { metabolism; Fatty acid elongation; Fatty acid } \\
\text { metabolism; Biosynthesis of unsaturated fatty acids; } \\
\text { Carbon metabolism; Lysine degradation; }\end{array}$ \\
\hline Q29RZ0 & ACAT1 & $\begin{array}{l}10 / 10 / \\
0\end{array}$ & mitochondria & 20 & 12 & $\begin{array}{l}\text { Synthesis and degradation of ketone bodies; Fatty } \\
\text { acid degradation; Valine, leucine and isoleucine } \\
\text { degradation; Tryptophan metabolism; Butanoate } \\
\text { metabolism; Terpenoid backbone biosynthesis; } \\
\text { Propanoate metabolism; Glyoxylate and } \\
\text { dicarboxylate metabolism; Pyruvate metabolism; } \\
\text { Fatty acid metabolism; Lysine degradation; Carbon } \\
\text { metabolism; }\end{array}$ \\
\hline Q32LG3 & $\mathrm{MDH} 2$ & $6 / 6 / 0$ & mitochondria & 20 & 5 & $\begin{array}{l}\text { Glyoxylate and dicarboxylate metabolism; Cysteine } \\
\text { and methionine metabolism; Pyruvate metabolism; } \\
\text { Citrate cycle (TCA cycle); Carbon metabolism; }\end{array}$ \\
\hline P12344 & GOT2 & $\begin{array}{l}11 / 10 / \\
1\end{array}$ & mitochondria & 14 & 11 & $\begin{array}{l}\text { 2-Oxocarboxylic acid metabolism; Alanine, } \\
\text { aspartate and glutamate metabolism; } \\
\text { Biosynthesis of amino acids; Arginine } \\
\text { biosynthesis; Tyrosine metabolism; Arginine } \\
\text { and proline metabolism; Phenylalanine, } \\
\text { tyrosine and tryptophan biosynthesis; Fat } \\
\text { digestion and absorption; Cysteine and } \\
\text { methionine metabolism; Carbon metabolism; } \\
\text { Phenylalanine metabolism; }\end{array}$ \\
\hline F1ML89 & CPS1 & $\begin{array}{l}11 / 10 / \\
1\end{array}$ & mitochondria & 12 & 5 & $\begin{array}{l}\text { Nitrogen metabolism; Alanine, aspartate and } \\
\text { glutamate metabolism; Biosynthesis of amino } \\
\text { acids; Arginine biosynthesis; Carbon metabolism; }\end{array}$ \\
\hline Q2KIE6 & HMGCS2 & $\begin{array}{l}11 / 10 / \\
1\end{array}$ & mitochondria & 11 & 4 & $\begin{array}{l}\text { Synthesis and degradation of ketone bodies; } \\
\text { Valine, leucine and isoleucine degradation; } \\
\text { Butanoate metabolism; Terpenoid backbone } \\
\text { biosynthesis; }\end{array}$ \\
\hline
\end{tabular}

a Number of all differentially acetylated sites (All) in the protein, higher acetylated sites (Up) and lower acetylated sites (Down) in the protein, separated by slash ${ }^{\mathrm{b}}$ Number of the nodes that were showing the reciprocally interactive proteins in the protein-protein interaction (PPI) network obtained by STRING analysis (shown as in Fig. 6 and/or Fig. S3)

downstreamly targeted by the transcription factor PPAR $\alpha$, which mediating the fatty acid beta-oxidation, associated with lipid catabolism. Results in the study show that EHHADH have two acetylation sites, there were 53 other proteins in the EHHADH's interaction network (Fig. 6, Table 3), which was the most frequent interactive protein in the network. EHHADH can participate in all different important hepatic metabolism processes, such as fatty acid degradation, valine, leucine, and isoleucine degradation; tryptophan metabolism; peroxisome; beta-alanine metabolism; butanoate metabolism; PPAR signaling pathway; propanoate metabolism; fatty acid metabolism; lysine degradation; and carbon metabolism. HADHA, an alpha subunit of a mitochondrial protein, catalyzes the last three steps of mitochondrial beta-oxidation of long-chain fatty acids. The interaction network show that HADHA interacts with 48 proteins (Fig. 6, Table 3), such as lipid metabolism-related protein HADHB, ACAT2, ACAT1, ACADVL, ACADM, and EHHADH. HADHA is also involved in hepatic metabolism associated pathways, such as fatty acid metabolism and biosynthesis, carbon metabolism, and amino acid degradation. Similar to EHHADH and HADHA, ACAT1, an enzyme catalyzing acetyl-CoA production, also participates in mitochondria-associated metabolic pathways. This suggests dysfunction of these important proteins via acetylation modification might destroy the metabolic processes, such as tricarboxylic acid cycle, thereby contributing to the development of fatty liver disease in dairy cows. 


\section{Discussion}

\section{Fatty liver in dairy cows}

The liver is the central organ regulating the metabolic balance of carbohydrate, fat, and protein in mammals [16-18]. The energy metabolism balance is particularly important during the parturition period for dairy cattle, and the energy and substance metabolism is pointfocused on the liver [19-21]. In the postperinatal period, the lactation of the cows slowly increases and therefore increases the body lactose consumption easily causing the cow is susceptible to experiencing an insufficient sugar supply, thus promoting fat mobilization in liver [22-26]. On the one hand, a large amount of fat mobilization promotes gluconeogenesis, increases the blood sugar concentration, and alleviates the negative energy balance. However, on the other hand, the enhanced fat mobilization promotes the dramatic increase of non-esterified fatty acids (NEFA) in the liver [21]. These NEFAs are partly oxidized in the liver and partly re-esterified to synthesize triglycerides (TG), which is difficult to be transported out of the liver by very-lowdensity lipoprotein (VLDL) [27]. Especially for dairy cattle, the lack of adequate lipid and liver esterase in the liver limits the hydrolysis of TAG, which leads to the excessive accumulation of TAG in the liver [23, 28-30], therefore resulting in susceptibility to fatty liver disease. While, nonalcoholic fatty liver disease (NAFLD) occurring in human beings, metabolic disorder syndromes and obesity are also usually the main causes, with increased plasma insulin and fatty acid concentration, elevated fasting aminotransferase (AST/ALT) and/or triglycerides level, and also abnormal lipid accumulation in the liver [31, 32]. In addition, another of the most important risk factors is histological evidence of hepatic inflammation [33, 34] caused by acute inflammation and subacute inflammation [35]. Thus, dairy cows with fatty liver disease is a typical NAFLD animal model, good for revealing the pathology and pathogenesis of NAFLD [15]. The objective of the study is to reveal the molecular mechanism of pathogenesis for NAFLD by taking fatty liver diseased dairy cattle as research model, identifying potential important biological pathways and protein targets, and thereby further discovering the therapeutic targets.

\section{Liver acetylome profiling identified important biological pathways regulating the pathogenesis of fatty liver in dairy cows}

Acetylome profiling of liver revealed the modification of protein acetylation in fatty livers (FL) was significantly different from normal (Norm) livers. Enrichment analysis of identified DAPs indicated that the protein modifications of the acetylation levels remarkably participated in the regulation of energy metabolic pathways, such as amino acid metabolism, carbon metabolism, citrate cycle, butanoate metabolism, glyoxylate and dicarboxylate metabolism, fatty acid degradation, pyruvate metabolism, and synthesis and degradation of ketone bodies (Fig. 4). Actually, the fatty liver disease occurred in dairy cows during their perinatal period is usually complicated by a high incidence of ketosis [36], with increased ketone body produced in the liver. All the possible dysregulated energy metabolic processes might be the direct cause for metabolism disorder and fat accumulation in livers of dairy cows. Moreover, the proteins in pathways that are closely associated with tricarboxylic acid cycle, such as valine, leucine, and isoleucine degradation, D-Glutamine and D-glutamate metabolism, lysine degradation, phenylalanine metabolism, alanine, aspartate, and glutamate metabolism, and arginine biosynthesis, also showed significantly increased acetylation levels (Fig. 5). It may be that the enhancements of the tricarboxylic acid cycle leads to an increase of $\alpha$-ketoglutarate and oxaloacetic acid metabolism, which indirectly leads to the upregulation of these amino acid metabolism pathways. Higher and/or lower acetylated proteins are significantly enriched in pathways related to energy and substance metabolism and/or biosynthesis, drug metabolism and cancer related pathways (Fig. 4). Human nonalcoholic fatty liver disease (NAFLD) has four stages: simple steatosis, non-alcoholic steatohepatitis (NASH), cirrhosis, and hepatocellular carcinoma. Simple fatty liver is a benign stage of NAFLD and can be reversed by treatment. About $10-20 \%$ of simple fatty liver develops into NASH [37]. At present, NASH is an important link in the development of NAFLD for end-stage liver disease, such as cirrhosis, hepatocellular carcinoma, and liver failure [38]. Therefore, acetylation modification of proteins that are involved in metabolic pathways may be responsible for the increasing severity of fatty liver disease.

\section{Acetylation of proteins locates in the mitochondria contributes to the development of fatty liver disease in dairy cows}

Since lysine acetylation is an important post-translational modification of proteins, it has been extensively studied for 50 years for its regulatory mechanisms in animals [8]. Proteins can gain or remove its enzymatic activity or specificity to certain substrates via acetylation or deacetylation, thereby regulating the energy and substance metabolism. Currently, However, little is known about the protein acetylome of fatty liver disease caused by negative energy balance in dairy cows, while there are relatively more studies in human and mouse liver tissues [39]. In this study, acetylome profiling of fatty livers revealed that $46.6 \%$ of the differentially expressed acetylated sites were localized in mitochondria, while $84.3 \%$ of the higher acetylated sites were localized to the mitochondria (Fig. 2), 
suggesting that the acetylation modification of hepatic proteins located in mitochondria plays a crucial role in both lipid and amino acid metabolism disorder in dairy cows, thereby contributes to the pathogenesis of fatty liver disease. In recent years, mitochondrial protein acetylation has received more attention. A study disclosed that $63 \%$ of mouse mitochondrial proteins contained lysine acetylation sites [40], devoting to abnormal mitochondrial oxidation of fatty acids, which is responsible for the degeneration of fatty liver disease [16]. Another study in mice showed that a high-fat diet could cause the hyperacetylation of liver mitochondrial oxygen metabolism-related proteins, leading to decreased activity of respiratory chain complexes [41]. It is presumed that mitochondrial protein acetylation would necessarily be considered as a potentially critical component of the mitochondrial metabolic regulatory network.

Actually, mitochondria are crucial for cellular energy metabolism processes, including the production of more than $90 \%$ of cellular ATP (respiratory chain), tricarboxylic acid cycle, $\beta$-oxidation, apoptosis, cell-cycle progression, proliferation and aging, and their dysfunction has been implicated in a wide range of metabolic diseases [36, 42-44]. Recently, a significant increase in protein lysine acetylation was found in pasture-fed Holstein-Friesian dairy cows during their early lactation period, accounting for impaired hepatic mitochrondrial function [45]. Low expression of sirtuin 1 (SIRT1), a NAD-dependent histone deacetylase, was indicated to promote hepatic fatty acid synthesis and inhibit fatty acid $\beta$-oxidation in dairy cows with mild fatty liver disease [46]. Histone acetyltransferses (HATs) and histone deacetylase (HDACs), as a senor of environmental nutrient and/or energy, balance the acetylation level of target proteins. Mammalian sirtuins (SIRTs) is an important type of NAD-dependent histone deacetylase, such as SIRT1 and SIRT3, were involved in oxidative stress and lipid metabolism regulation [47], and had been proposed as a reliable biomarker and/or therapeutic target for fatty liver disease [45-49]. It suggests that acetylation of mitochondrial protein was an emerging and fundamental mechanism regulating the development of fatty liver disease in dairy cows, through modifying the activities of mitochondrial proteins and overall mitochondrial function [47-49]. The mechanism how these acetylated proteins to be modified and their molecular function are involved in the pathogenesis of fatty liver disease will be necessarily elucidated in the future.

\section{Identification of candidate mitochondrial proteins as important regulation targets during the pathogenesis of fatty liver}

From the acetylated proteins, it was observed that some mitochondrial proteins are involved not only in the fatty liver-related disorder protein network but also in several lipid metabolism-related pathways (Table 3). Therefore, it was speculated that acetylation of these proteins plays a key role in the development of fatty liver disease of dairy cows. Especially, most of the mitochondrial proteins were achieved a higher acetylation level (Tables 2 and 3). For example, carbamoyl phosphate synthase (CPS1) is the catalytic enzyme of the first step in the urea cycle, which is very important for the removal of excess urea from cells. Previous proteomic studies on non-alcoholic fatty liver showed that serum concentration of CPS1 decreases gradually in the order of control steatosis and NASH patient subjects and CPS1 has been confirmed to be serum candidate markers of NAFLD [50]. Consistent with results in the present study, previous studies also have observed a significant upregulation of HADHA acetylation levels, modified by sirtuin 3 (SIRT3) [47], in the liver tissues of mice that were fed with a high-fat diet for 1 week [51]. Activation of PPAR $\alpha$ promotes lipolysis, and HADHA on the livers of hepatocyte humanized mice treated with PPAR $\alpha$ agonists is significantly upregulated at the level of mRNA [52]. The level of HADHA in human renal cell carcinoma, breast cancer, and hepatocellular carcinoma is significantly downregulated [53-55]. Another new important candidate protein ACAT1 was identified, because of its ample interactions with other functional proteins and also plenty acetylation sites (Fig. 6, Table 2). Previous studies have confirmed that ACAT1 plays a catalytic role in ketone decomposition and formation, fatty acid oxidation, and isoleucine degradation [56]. ACAT1 is also associated with anticancer resistance, cancer cell proliferation, and cancer growth [57]. ACAT1 is the key enzyme catalyzing the synthesis of cholesterol ester at the last step. Cholesterol ester is one of the core components of lipid droplets [58-60]. Similarly, 3-hydroxy-3-methylglutarylCoA synthase 2 (HMGCS2) was identified as a potential crucial biomarker for dairy cows suffering from ketosis. HMGCS2 is an important mitochondrial enzyme of ketogenesis, which is a metabolic process that provides lipid-derived energy for various organs during the carbohydrate deprivation. The significantly abnormal acetylation level of HMGCS2 in fatty livers (Table 3) indicated a ketone metabolism disorder in dairy cows with fatty liver disease. In addition, the expression of EHHADH is regulated by PPAR $\alpha$, which is involved in the tricarboxylic acid cycle and peroxisome fatty acid oxidation [61]. Proteome results showed that cows with a high propensity to mobilize fat had greater wholebody fat oxidation compared to healthy cows [62]. In addition to mitochondrial $\beta$ oxidation, fatty acid degradation in peroxisomes and microsomes increases proportionally. After the perinatal period, the fatty acid $\beta$ 
oxidative capacity of peroxisomes decreases [63]. Thus, EHHADH, a fairly new candidate protein, was identified to be potentially associated with the pathogenesis of fatty liver disease, for its abundant interaction networks with other proteins (Table 3).

\section{Conclusions}

In conclusion, this study provides a comprehensive acetylome profile of liver in dairy cattle and reveals important mitochondria-associated pathways that are involved in the regulation of the pathogenesis of fatty liver disease, including the TCA cycle, propionate metabolism, glycolysis/gluconeogenesis, pyruvate metabolism, oxidative phosphorylation, fatty acid degradation, valine, leucine, and isoleucine degradation, drug metabolism cytochrome P450, and the PPAR signaling pathway. Furthermore, this study identified potential important proteins, such as HADHA, ACAT1, and EHHADH, which may be important regulatory factors being acetylation level modified in the development of fatty liver disease in dairy cows, potentially being therapeutic targets for NAFLD in human beings. However, further investigation is needed to focus on its molecular mechanism of regulating the hepatic metabolism. In the future, proteomic analyses would be necessary to combine with acetylomic analyses, so as to further uncover the important regulatory function of acetylation modification on liver function.

\section{Methods}

\section{Ethics statement}

All animal experiments were carried out according to the Regulations for the Administration of Affairs Concerning Experimental Animals published by the Ministry of Science and Technology, China (2004), and were approved by the Shandong Agricultural University Animal Care and Use Committee (approval number, SDAUA-2017-044).

\section{Sample collection}

Dairy cows at $7 \pm 2$ days $(n=24)$ post parturition, with similar body weights, body conformation condition scores, and less than three parity were selected for liver biopsy $[5,60]$. The cows were housed in a free stall barn with constant access to water and feed at a farm affilated to Holstein Cattle Association in Shandong Province. Before the liver biopsy procedure, the dairy cows were held in a cage and shaved on their side at the intersection of the 10th-11th rib and the middle humerus to the hip tubercle with an area of $5 \times 5 \mathrm{~cm}[45,64]$. After sanitization, subcutaneous injection of $500 \mathrm{mg}$ of $0.5 \%$ procaine was provided for local anesthesia. Next, the skin was cut with an incision of $0.5-1 \mathrm{~cm}$ in length, followed by the liver biopsy process operated by a veterinary surgeon $[34,36]$. The liver tissues were biopsied using the Bard Magnum biopsy system (Bard Peripheral Vascular, Inc., Tempe, AZ, US) followed by surgical suturing of the skin. The animal was administered ketoprofen and penicillin G procaine by intravenous injection immediately after biopsy. The same injection protocol was performed for the next 3 to 5 days, and the animal was monitored for up to 2 weeks depending on its condition until complete recovery of health. Liver tissue samples were immediately snapfrozen in liquid nitrogen for later analysis or fixed in 5\% polyformaldehyde for oil red $\mathrm{O}$ staining.

The biopsied dairy cattle had their fatty liver condition diagnosed according to the average percentage of hepatic cells containing lipid droplets in the tissue, and other background information of these cows including production and serum biochemical indexes [1,60] was shown in Table S2. As a result, six samples were diagnosed as normal liver $(6.26 \pm 5.23 \%)$ and eight as severe fatty liver $(86.75 \pm 4.83 \%)$. These normal liver samples (Norm) and/or fatty liver samples (FL) were randomly regrouped in an equal proportion for acetylome analysis, named as Norm1, Norm2, Norm3, and FL1, FL2, FL3, respectively.

\section{Protein extraction and trypsin digestion}

The sample was retrieved from $-80^{\circ} \mathrm{C}$ conditions, an appropriate amount of tissue sample was weighed into a liquid nitrogen pre-cooled mortar, and the liquid nitrogen was sufficiently ground to a powder. Each group of samples was separately added to a powder of four volumes of lysis buffer (8 M urea, 1\% protease inhibitor, $3 \mu \mathrm{M}$ TSA, $50 \mathrm{mM}$ NAM, and $2 \mathrm{mM}$ EDTA) and sonicated. After centrifugation at $12,000 \mathrm{~g}$ for $10 \mathrm{~min}$ at $4{ }^{\circ} \mathrm{C}$, the cell debris was removed, the supernatant was transferred to a new centrifuge tube, and the protein concentration was determined using a BCA kit.

For digestion, the protein solution was reduced with 5 $\mathrm{mM}$ dithiothreitol for $30 \mathrm{~min}$ at $56^{\circ} \mathrm{C}$ and alkylated with $11 \mathrm{mM}$ iodoacetamide for $15 \mathrm{~min}$ at room temperature in darkness. The protein sample was then diluted by adding $100 \mathrm{mM}$ TEAB to urea with a concentration of less than $2 \mathrm{M}$. Finally, trypsin was added at a ratio of 1 : 50 trypsin-to-protein mass for the first digestion overnight and 1:100 trypsin-to-protein mass ratio for a second $4 \mathrm{~h}$ digestion.

\section{TMT labeling and HPLC fractionation}

After trypsin digestion, the peptide was desalted by Strata X C18 SPE column (Phenomenex) and vacuum dried. The peptide was reconstituted in 0.5 M TEAB and processed according to the manufacturer's protocol for the TMT kit. The tryptic peptides were fractionated by 
high $\mathrm{pH}$ reverse-phase HPLC using a Thermo Betasil C18 column (5 $\mu \mathrm{m}$ particles, $10 \mathrm{~mm}$ ID, $250 \mathrm{~mm}$ length).

\section{Affinity enrichment of lysine-acetylated peptides}

The peptide segment was dissolved in the IP buffer solution $(100 \mathrm{mM} \mathrm{NaCl}, 1 \mathrm{mM}$ EDTA, $50 \mathrm{mM}$ Tris- $\mathrm{HCl}$, $0.5 \% \mathrm{NP}-40, \mathrm{pH} 8.0)$. The supernatant was transferred to the acetylated resin (PTM104, Hangzhou Jingjie Biotechnology Co., Ltd., PTM Bio), which was washed in advance, and incubated overnight at $4{ }^{\circ} \mathrm{C}$ on a shaker. After incubation, the resin was washed four times with IP buffer solution and then twice with deionized water. Finally, the resin-bound peptide segments were eluted with $0.1 \%$ trifluoroacetic acid eluent three times. The eluent was collected and vacuum freeze-dried. After drying, desalination was carried out according to C18 ZipTips instructions. After vacuum freeze-drying, the samples were analyzed by liquid chromatography-mass spectrometry (LC-MS).

\section{LC-MS/MS analysis}

The tryptic peptides were dissolved in $0.1 \%$ formic acid (solvent A) and directly loaded onto a homemade reversed-phase analytical column $(15 \mathrm{~cm}$ length, $75 \mu \mathrm{m}$, i.d.) at a constant flow rate of $400 \mathrm{~nL} / \mathrm{min}$ on an EASYnLC 1000 UPLC system. The gradient comprised solvent B with a series of treatments: 6 to $23 \%$ (0.1\% formic acid in $98 \%$ acetonitrile) for $26 \mathrm{~min}, 23$ to $35 \%$ for $8 \mathrm{~min}$, and up to $80 \%$ for $3 \mathrm{~min}$, followed by holding at $80 \%$ for the last $3 \mathrm{~min}$.

The peptides were subjected to an NSI source followed by tandem mass spectrometry (MS/MS) in Q ExactiveTM Plus (Thermo) coupled online to the UPLC. The electrospray voltage was $2.0 \mathrm{kV}$. The $\mathrm{m} / \mathrm{z}$ scan range was 350 to 1800 for a full scan, and intact peptides were detected in the Orbitrap at a resolution of 70,000. Peptides were then selected for MS/MS using the NCE setting as 28 , and the fragments were detected in the Orbitrap at a resolution of 17,500. A data-dependent procedure that alternated between one MS scan followed by $20 \mathrm{MS} / \mathrm{MS}$ scans with $15.0 \mathrm{~s}$ dynamic exclusion was followed. Automatic gain control (AGC) was set at 5E4. The fixed first mass was set as $100 \mathrm{~m} / \mathrm{z}$.

\section{Database search}

The resulting MS/MS data were processed using the Maxquant search engine (v.1.5.2.8). Tandem mass spectra were searched against the acetylation database concatenated with reverse decoy database. Trypsin/P was specified as a cleavage enzyme allowing up to four missing cleavages. The mass tolerance for precursor ions was set as $20 \mathrm{ppm}$ in First search and $5 \mathrm{ppm}$ in Main search, and the mass tolerance for fragment ions was set as $0.02 \mathrm{Da}$. Carbamidomethyl on Cys was specified as fixed modification, and acetylation modification and oxidation on Met were specified as variable modifications. FDR was adjusted to $<1 \%$, and the minimum score for modified peptides was set at $>40$.

Secondary mass spectrometry data were retrieved using Maxquant (v1.5.2.8). Retrieval parameter settings: UniProt Bos Taurus (24,215 sequences) was used as the database, anti-library was added to calculate the false positive rate (FDR) caused by random matching, and common contamination database was added to the database to eliminate the influence of contaminated proteins in identification results; restriction mode was set to Trypsin/P; number of missing sites was set to be Tryp$\sin /$ P. 2. The minimum length of the peptide segment was set to seven amino acid residues; the maximum modification number of the peptide segment was set to five; the mass error tolerance of the primary parent ions of the First search and Main search was set to 20 and 5 $\mathrm{ppm}$, respectively, and the mass error tolerance of the secondary fragment ions was $0.02 \mathrm{Da}$. Alkylation of cysteine was set as fixed modification, which could be changed into oxidation of methionine and acetylation of the $\mathrm{N}$-terminal of protein. The quantitative method was set to TMT- 6 plex, and the FDR of protein identification and PSM identification was set to $1 \%$.

\section{Bioinformatics analysis}

The functions and characteristics of these proteins are explained in detail from the aspects of Gene Ontology (GO), and the annotation proteome was derived from the UniProt-GOA database (http://www.ebi.ac.uk/GOA/ ). First, the identified protein ID was converted to UniProt ID and then mapped to GO IDs by protein ID. Then, proteins were classified by Gene Ontology annotation based on three categories: biological process, cellular component, and molecular function. Identified protein domain functional descriptions were annotated by InterProScan (a sequence analysis application) based on the protein sequence alignment method, and the InterPro domain database was used. The KEGG pathway database was used to annotate the protein pathway. First, the KEGG online service tool KAAS was used to annotate the submitted protein, and then match the annotated protein into the corresponding pathway in the database through the KEGG mapper. Wolfpsort, software for predicting subcellular localization, was used to annotate the subcellular localization of the submitted proteins. Soft motif-x was used to analyze the model of sequences constituted with amino acids in specific positions of modify-21-mers (ten amino acids upstream and downstream of the site, but phosphorylation with modify-13-mers have six amino acids upstream and downstream of the site) in all protein sequences. All the database protein sequences were used as background 
database parameters, and the other parameters were maintained at the default settings.

All sequences of differentially expressed proteins were searched against the STRING database (version 10.5) for protein-protein interactions. Only interactions between the proteins belonging to the searched dataset were selected, thereby excluding external candidates. STRING defines a metric called "confidence score". To define the interaction confidence, all interactions that had a confidence score $\geq 0.7$ (high confidence) were gathered. A graph of theoretical clustering algorithm, molecular complex detection (MCODE), was utilized to analyze densely connected regions.

For further hierarchical clustering based on differentially modified protein functional classification (such as GO, Domain, Pathway), all the categories obtained after enrichment were collated, along with their $P$ values, and then filtered for those categories that were at least enriched in one of the clusters with $P$-value $<0.05$. This filtered $\mathrm{P}$-value matrix was transformed by the function $\mathrm{x}=-\log 10 \quad(P$-value $)$. Finally, these $\mathrm{x}$ values were $\mathrm{z}$ transformed for each functional category. These $\mathrm{z}$ scores were then clustered by one-way hierarchical clustering (Euclidean distance, average linkage clustering) in Genesis. Differentially expressed proteins were divided into four parts according to their differentially expressed multiples: Q1 $(0<$ Ratio $\leq 1 / 1.5)$, Q2 $(1 / 1.5<$ Ratio $\leq 1 /$ 1.2), Q3 $(1.2<$ Ratio $\leq 1.5)$, and Q4 (Ratio $>1.5)$. Cluster membership was visualized with a heat map using the "heatmap.2" function from the "gplots" R package.

\section{Supplementary information}

Supplementary information accompanies this paper at https://doi.org/10. 1186/s12864-020-06837-y

Additional file 1: Fig. S1. Data reliability testing. Fig. S2. Gene Ontology (GO) functional annotation of differentially acttylated proteins at lysines. Fig. S3. Identification of highly enriched protein-protein interaction clusters.

Additional file 2: Table S1. List of differentially expressed acetylated proteins identified and quantified by the TMT analysis in the study.

Additional file 3: Table S2. Production information of normal (Norm) and fatty liver dairy cows that were liver biopsied and their serum biochemical parameters ${ }^{1}$.

\footnotetext{
Abbreviations

GO: Gene Ontology; KEGG: Kyoto Encyclopedia of Genes and Genomes; Kac: Lysine acetylated; DAPs: Differentially acetylated proteins; NEFA: Nonesterified fatty acids; HADHA: HADHA protein; ACAT1: Acetyl-CoA acetyltransferase; EHHADH: Enoyl-CoA hydratase and 3-hydroxyacyl CoA dehydrogenase; ANXA6: Annexin A6; CPS1: Carbamoyl-phosphate synthase 1; GOT2: Aspartate aminotransferase; HMGCS2: Hydroxymethylglutaryl-CoA synthase; HADHB: Trifunctional enzyme subunit beta; ACAA2: 3-ketoacyl-CoA thiolase; ACADM: Medium-chain specific acyl-CoA dehydrogenase; ACADVL: Very long-chain specific acyl-CoA dehydrogenase:

PCK2: Phosphoenolpyruvate carboxykinase 2; IDH2: Isocitrate dehydrogenase (NADP); MDH2: Malate dehydrogenase; SUCLG1: Succinate-CoA ligase (ADP/ GDP-forming) subunit alpha; FABP1: Fatty acid-binding protein; SCP2: Non-
}

specific lipid-transfer protein; TAG: Triglycerides; VLDL: Very-low-density lipoprotein

\section{Acknowledgements}

We thank Dr. Jinming Huang (Dairy Cattle Research Center, Shandong Academy of Agricultural Sciences), Dr. Gao Yundong, Dr. Jianbin Li (Shandong OX Liverstock Breeding Co., Ltd), Dr. Ying Yu (China Agricultural University) for their assistance in recruiting the tissue samples for the study. We also appreicate Hangzhou Jingjie Biotechnology Co., Ltd., PTM Bio for the assistance in the data analysis. We thank Elseviewer for its linguistic assistance during the preparation of this manuscript.

\section{Authors' contributions}

$\mathrm{LZ}, \mathrm{CH}$, and $\mathrm{KS}$ participated in the execution of all experiments, analyzed the data, and drafted the manuscript; CH, LZ, KS, XZ, YZ, SW, ZX, RL and TL participated in the fatty liver disease investigation and liver sample collection; KS, QZ, LZ, XZ, ZY, ZX and ZW participated in experimental design, coordinated the experiments. QZ, ZW, QW and ZS participated in data analysis and discussion. All authors reviewed and approved the final manuscript.

\section{Funding}

The work was supported by the Key Project of Agricultural Fine Breeding of Shandong Province (2019LZGC011, 2016LZGC030), National Natural Science Foundation of China (31402054), Shandong Natural Science Foundation (ZR2013CM013), Funds of Shandong "Double Tops" Program

(SYL2017YSTD08), the Modern Agricultural Industry Technology System (CARS-36) and the Tai Mountain Scholar Inovation Team. The funding body did not play a role in the design of the study and collection, analysis, and interpretation of data and in writing the manuscript.

\section{Availability of data and materials}

The data used to support the findings of this study are available from the corresponding author upon request.

\section{Ethics approval and consent to participate}

All process was completed on the basis of the Guidelines for Care and Use of Laboratory Animals of Shandong Agricultural University and approved by the Animal Ethics Committee of Shandong Agricultural University. We have obtained written informed consent from the animal owner to use these animals in the study.

\section{Consent for publication}

Not applicable.

\section{Competing interests}

The authors declare that they have no conflicts of interest concerning this article.

Received: 23 January 2020 Accepted: 16 June 2020

Published online: 26 June 2020

\section{References}

1. Shi K, Niu F, Zhang Q, Ning C, Yue S, Hu C, Xu Z, Wang S, Li R, Hou Q, et al. Identification of whole-genome significant single nucleotide polymorphisms in candidate genes associated with serum biochemical traits in Chinese Holstein cattle. Front Genet. 2020;11:163.

2. White HM. The role of TCA cycle anaplerosis in ketosis and fatty liver in periparturient dairy cows. Animals (Basel). 2015;5(3):793-802.

3. Bobe G, Young JW, Beitz DC. Invited review: pathology, etiology, prevention, and treatment of fatty liver in dairy cows. J Dairy Sci. 2004;87(10):3105-24.

4. Tharwat M, Endoh D, Oikawa S. Hepatocyte apoptosis in dairy cows with fatty infiltration of the liver. Res Vet Sci. 2012;93(3):1281-6.

5. Yue SJ, Zhao YQ, Gu XR, Yin B, Jiang YL, Wang ZH, Shi KR. A genome-wide association study suggests new candidate genes for milk production traits in Chinese Holstein cattle. Anim Genet. 2017;48(6):677-81.

6. Shen Y, Wei W, Zhou DX. Histone acetylation enzymes coordinate metabolism and gene expression. Trends Plant Sci. 2015;20(10):614-21.

7. Lin H, Su X, He B. Protein lysine acylation and cysteine succination by intermediates of energy metabolism. ACS Chem Biol. 2012;7(6):947-60. 
8. Narita T, Weinert BT, Choudhary C. Functions and mechanisms of nonhistone protein acetylation. Nat Rev Mol Cell Biol. 2019;20(3):156-74.

9. Nambi S, Gupta K, Bhattacharyya M, Ramakrishnan P, Ravikumar V, Siddiqui N, Thomas AT, Visweswariah SS. Cyclic AMP-dependent protein lysine acylation in mycobacteria regulates fatty acid and propionate metabolism. J Biol Chem. 2013;288(20):14114-24.

10. Hart GW, Ball LE. Post-translational modifications: a major focus for the future of proteomics. Mol Cell Proteomics. 2013;12(12):3443.

11. Zhao S, Xu W, Jiang W, Yu W, Lin Y, Zhang T, Yao J, Zhou L, Zeng Y, Li H, et al. Regulation of cellular metabolism by protein lysine acetylation. Science. 2010;327(5968):1000-4.

12. Lee JV, Carrer A, Shah S, Snyder NW, Wei S, Venneti S, Worth AJ, Yuan ZF, Lim HW, Liu S, et al. Akt-dependent metabolic reprogramming regulates tumor cell histone acetylation. Cell Metab. 2014;20(2):306-19.

13. Lin R, Tao R, Gao X, Li T, Zhou X, Guan KL, Xiong Y, Lei QY. Acetylation stabilizes ATP-citrate lyase to promote lipid biosynthesis and tumor growth. Mol Cell. 2013;51(4):506-18

14. Zhang L, Yao W, Xia J, Wang T, Huang F. Glucagon-induced acetylation of energy-sensing factors in control of hepatic metabolism. Int J Mol Sci. 2019; 20(8):1885.

15. Shi K, Li R, Xu Z, Zhang Q. Identification of crucial genetic factors, such as PPARY, that regulate the pathogenesis of fatty liver disease in dairy cows is imperative for the sustainable development of dairy industry. Animals (Basel). 2020;10(4):639.

16. Koo SH. Nonalcoholic fatty liver disease: molecular mechanisms for the hepatic steatosis. Clin Mol Hepatol. 2013;19(3):210-5.

17. Fu C, Liu L, Li F. Acetate alters the process of lipid metabolism in rabbits. Animals (Basel). 2018;12(9):1895-902.

18. Liu L, Fu C, Li FC. Dietary niacin supplementation suppressed hepatic lipid accumulation in rabbits. Asian Austral J Anim. 2016;29(12):1748-55.

19. Liu L, Fu C, Li F. Acetate Affects the process of lipid metabolism in rabbit liver, skeletal muscle and adipose tissue. Animals (Basel). 2019;9(10):799.

20. Jiang F, Lin X, Yan Z, Hu Z, Wang Y, Wang Z. Effects of forage source and particle size on feed sorting, milk production and nutrient digestibility in lactating dairy cows. J Anim Physiol Anim Nutr (Berl). 2018;102(6):1472-81.

21. Hu ZY, Yin ZY, Lin XY, Yan ZG, Wang ZH. Effects of feeding fatty acid calcium and the interaction of forage quality on production performance and biochemical indexes in early lactation cow. J Anim Physiol Anim Nutr (Berl). 2015;99(5):899-904.

22. Jorritsma $\mathrm{R}$, Jorritsma $\mathrm{H}$, Schukken $\mathrm{YH}$, Wentink $\mathrm{GH}$. Relationships between fatty liver and fertility and some periparturient diseases in commercial Dutch dairy herds. Theriogenology. 2000;54(7):1065-74.

23. Katoh N. Relevance of apolipoproteins in the development of fatty liver and fatty liver-related peripartum diseases in dairy cows. J Vet Med Sci. 2002; 64(4):293-307

24. Kobayashi Y, Boyd CK, McCormack BL, Lucy MC. Reduced insulin-like growth factor-l after acute feed restriction in lactating dairy cows is independent of changes in growth hormone receptor 1 A mRNA. J Dairy Sci. 2002;85(4):748-54.

25. Du H, Wang C, Wang X, Ma M, Li F. The effects of dietary a-linolenic acid on growth performance, meat quality, fatty acid composition, and liver relative enzyme mRNA expression of growing meat rabbits. J Anim Feed Sci. 2013; 22:122-9.

26. Radcliff RP, McCormack BL, Keisler DH, Crooker BA, Lucy MC. Partial feed restriction decreases growth hormone receptor $1 \mathrm{~A}$ mRNA expression in postpartum dairy cows. J Dairy Sci. 2006;89(2):611-9.

27. Farid AS, Honkawa K, Fath EM, Nonaka N, Horii Y. Serum paraoxonase-1 as biomarker for improved diagnosis of fatty liver in dairy cows. BMC Vet Res. 2013:9:73.

28. Pullen DL, Liesman JS, Emery RS. A species comparison of liver slice synthesis and secretion of triacylglycerol from nonesterified fatty acids in media. J Anim Sci. 1990;68(5):1395-9.

29. Cui J, Zeng Y, Wang H, Chen W, Du J, Chen QM, et al. The effects of DGAT1 and DGAT2 mRNA expression on fat deposition in fatty and lean breeds of pig. Livest Sci. 2011;140:292-6.

30. Wang H, Wang J, Yang DD, Liu ZL, Zeng YQ, Chen W. Expression of lipid metabolism genes provides new insights into intramuscular fat deposition in Laiwu pigs. Asian Austral J Anim. 2020;33(3):390-7.

31. Nasr $P$, Ignatova $S$, Kechagias $S$, Ekstedt M. Natural history of nonalcoholic fatty liver disease: a prospective follow-up study with serial biopsies. Hepatol Commun. 2018;2(2):199-210.
32. Demir M, Lang S, Steffen HM. Nonalcoholic fatty liver disease - current status and future directions. J Dig Dis. 2015;16(10):541-57.

33. Bellentani S. The epidemiology of non-alcoholic fatty liver disease. Liver Int. 2017;37(Suppl 1):81-4

34. Du X, Liu G, Loor JJ, Fang Z, Bucktrout R, Yang Y, et al. Impaired hepatic autophagic activity in dairy cows with severe fatty liver is associated with inflammation and reduced liver function. J Dairy Sci. 2018;101(12):11175-85.

35. Bradford BJ, Yuan K, Farney JK, Mamedova LK, Carpenter AJ. Invited review: inflammation during the transition to lactation: new adventures with an old flame. J Dairy Sci. 2015;98(10):6631-50.

36. Du X, Chen L, Huang D, Peng Z, Zhao C, Zhang Y, et al. Elevated apoptosis in the liver of dairy cows with ketosis. Cell Physiol Biochem. 2017:43(2): 568-78.

37. Ekstedt M, Nasr P, Kechagias S. Natural history of NAFLD/NASH. Curr Hepatol Rep. 2017;16(4):391-7.

38. Schuster S, Cabrera D, Arrese M, Feldstein AE. Triggering and resolution of inflammation in NASH. Nat Rev Gastroenterol Hepatol. 2018;15(6):349-64.

39. Kim SC, Sprung R, Chen Y, Xu Y, Ball H, Pei J, Cheng T, Kho Y, Xiao H, Xiao L, et al. Substrate and functional diversity of lysine acetylation revealed by a proteomics survey. Mol Cell. 2006;23(4):607-18.

40. Baeza J, Smallegan MJ, Denu JM. Mechanisms and dynamics of protein acetylation in mitochondria. Trends Biochem Sci. 2016;41(3):231-44.

41. Kendrick AA, Choudhury M, Rahman SM, McCurdy CE, Friederich M, Van Hove JL, Watson PA, Birdsey N, Bao J, Gius D, et al. Fatty liver is associated with reduced SIRT3 activity and mitochondrial protein hyperacetylation. Biochem J. 2011;433(3):505-14.

42. Zhai R, Dong X, Feng L, Li S, Hu Z. The effect of heat stress on autophagy and apotosis of rumen, abomasum, duodenum, liver and kidney cells in calves. Animals (Basel). 2019;9:85.

43. Dong X, Zhai R, Liu Z, Lin X, Wang Z, Hu Z. The effect of intravenous infusions of glutamine on duodenal cell autophagy and apoptosis in earlyweaned calves. Animals (Basel). 2019;9(7):404.

44. Anderson KA, Hirschey MD. Mitochondrial protein acetylation regulates metabolism. Essays Biochem. 2012;52:23-35.

45. Garcia-Roche M, Casal A, Mattiauda DA, Ceriani M, Jasinsky A, Mastrogiovanni M, Trostchansky A, Carriquiry M, Cassina A, Quijano C. Impaired hepatic mitochondrial function during early lactation in dairy cows: association with protein lysine acetylation. PLoS One. 2019;14(3): e213780.

46. Li Y, Zou S, Ding H, Hao N, Huang Y, Tang J, Cheng J, Feng S, Li J, Wang X, et al. Low expression of sirtuin 1 in the dairy cows with mild fatty liver alters hepatic lipid metabolism. Animals (Basel). 2020;10(4):560.

47. Zhang Y, Zhou F, Bai M, Liu Y, Zhang L, Zhu Q, Bi Y, Ning G, Zhou L, Wang $X$. The pivotal role of protein acetylation in linking glucose and fatty acid metabolism to beta-cell function. Cell Death Dis. 2019;10(2):66.

48. He X, Gao J, Hou H, Qi Z, Chen H, Zhang XX. Inhibition of mitochondrial fatty acid oxidation contributes to development of nonalcoholic fatty liver disease induced by environmental cadmium exposure. Environ Sci Technol. 2019;53(23):13992-4000.

49. Guo L, Zhou SR, Wei XB, Liu Y, Chang XX, Liu Y, Ge X, Dou X, Huang HY, Qian SW, et al. Acetylation of mitochondrial trifunctional protein alphasubunit enhances its stability to promote fatty acid oxidation and is decreased in nonalcoholic fatty liver disease. Mol Cell Biol. 2016;36(20): 2553-67.

50. Rodriguez-Suarez E, Duce AM, Caballeria J, Martinez AF, Fernandez E, Gomara C, Alkorta N, Ariz U, Martinez-Chantar ML, Lu SC, et al. Nonalcoholic fatty liver disease proteomics. Proteomics Clin Appl. 2010;4(4):36271

51. Thapa D, Wu K, Stoner MW, Xie B, Zhang M, Manning JR, Lu Z, Li JH, Chen Y, Gucek M, et al. The protein acetylase GCN5L1 modulates hepatic fatty acid oxidation activity via acetylation of the mitochondrial beta-oxidation enzyme HADHA. J Biol Chem. 2018;293(46):17676-84.

52. de la Rosa RM, Sugahara G, Hooiveld G, Ishida Y, Tateno C, Kersten S. The whole transcriptome effects of the PPARalpha agonist fenofibrate on livers of hepatocyte humanized mice. BMC Genomics. 2018;19(1):443.

53. Zhao Z, Lu J, Han L, Wang X, Man Q, Liu S. Prognostic significance of two lipid metabolism enzymes, HADHA and ACAT2, in clear cell renal cell carcinoma. Tumour Biol. 2016;37(6):8121-30

54. Mamtani M, Kulkarni H. Association of HADHA expression with the risk of breast cancer: targeted subset analysis and meta-analysis of microarray data. BMC Res Notes. 2012;5:25. 
55. Kim SY, Lee PY, Shin HJ, Kim DH, Kang S, Moon HB, Kang SW, Kim JM, Park SG, Park BC, et al. Proteomic analysis of liver tissue from $\mathrm{HBx}$-transgenic mice at early stages of hepatocarcinogenesis. Proteomics. 2009;9(22):5056-66.

56. Abdelkreem E, Akella R, Dave U, Sane S, Otsuka H, Sasai H, Aoyama Y, Nakama M, Ohnishi H, Mahmoud S, et al. Clinical and mutational characterizations of ten indian patients with beta-ketothiolase deficiency. JIMD Rep. 2017;35:59-65.

57. Goudarzi A. The recent insights into the function of ACAT1: a possible anticancer therapeutic target. Life Sci. 2019;232:116592.

58. Bhatt-Wessel B, Jordan TW, Miller JH, Peng L. Role of DGAT enzymes in triacylglycerol metabolism. Arch Biochem Biophys. 2018;655:1-11.

59. Yang W, Bai Y, Xiong Y, Zhang J, Chen S, Zheng X, Meng X, Li L, Wang J, XU $C$, et al. Potentiating the antitumour response of CD8(+) T cells by modulating cholesterol metabolism. Nature. 2016;531(7596):651-5.

60. Yan Z, Wang Z, Zhang Q, Yue S, Yin B, Jiang Y, Shi K. Identification of whole-genome significant single nucleotide polymorphisms in candidate genes associated with body conformation traits in Chinese Holstein cattle. Anim Genet. 2020;51(1):141-6.

61. Houten SM, Denis S, Argmann CA, Jia Y, Ferdinandusse S, Reddy JK, Wanders RJ. Peroxisomal L-bifunctional enzyme (Ehhadh) is essential for the production of medium-chain dicarboxylic acids. J Lipid Res. 2012;53(7): 1296-303.

62. Borner S, Albrecht E, Schaff C, Hacke S, Kautzsch U, Derno M, Hammon HM, Rontgen M, Sauerwein H, Kuhla B. Reduced AgRP activation in the hypothalamus of cows with high extent of fat mobilization after parturition. Gen Comp Endocrinol. 2013;193:167-77.

63. Grum DE, Drackley JK, Clark JH. Fatty acid metabolism in liver of dairy cows fed supplemental fat and nicotinic acid during an entire lactation. J Dairy Sci. 2002;85(11):3026-34.

64. Carriquiry M, Weber WJ, Fahrenkrug SC, Crooker BA. Hepatic gene expression in multiparous Holstein cows treated with bovine somatotropin and fed n-3 fatty acids in early lactation. J Dairy Sci. 2009;92(10):4889-900.

\section{Publisher's Note}

Springer Nature remains neutral with regard to jurisdictional claims in published maps and institutional affiliations.

Ready to submit your research? Choose BMC and benefit from:

- fast, convenient online submission

- thorough peer review by experienced researchers in your field

- rapid publication on acceptance

- support for research data, including large and complex data types

- gold Open Access which fosters wider collaboration and increased citations

- maximum visibility for your research: over $100 \mathrm{M}$ website views per year

At $\mathrm{BMC}$, research is always in progress.

Learn more biomedcentral.com/submissions 